\title{
ICRF heating schemes for the ITER non-active phase
}

\author{
Mireille Schneider ${ }^{1, *}$, Jean-François Artaud $^{2}$, Paul Bonoli ${ }^{3}$, Yevgen Kazakov $^{4}$, Philippe Lamalle ${ }^{1}$, Ernesto Lerche ${ }^{4,5}$, \\ Dirk Van Eester ${ }^{4}$ and John Wright ${ }^{3}$ \\ 1 ITER Organization, Route de Vinon-sur-Verdon, CS 90 046, 13067 St. Paul-lez-Durance, France \\ 2 CEA, IRFM, F-13108 Saint Paul-lez-Durance, France \\ 3 Plasma Science and Fusion Center, MIT, Cambridge, MA 02139, USA \\ 4 LPP-ERM/KMS, Association Eurofusion-Belgian State, TEC partner, Brussels, Belgium \\ 5 Euratom/CCFE Fusion Association, Culham Science Centre, Abingdon, United Kingdom
}

\begin{abstract}
ITER plasma operation requires a non-active phase for tokamak initial commissioning, covering First Plasma and Pre-Fusion Power Operation phases, PFPO-1 and PFPO-2. Non-active operation consists of hydrogen and helium plasmas to minimize the neutron production rate. The present document describes some Ion Cyclotron Radio Frequency (ICRF) heating schemes in terms of their predicted performance for the main foreseen scenarios of the ITER non-active phase in hydrogen and helium. Emphasis is given on remaining issues and physics uncertainties to be addressed for successful ICRF heating in ITER.
\end{abstract}

\section{Introduction}

Auxiliary heating power is essential for future tokamaks to achieve and sustain fusion performance. In ITER, three auxiliary heating methods are foreseen: Electron Cyclotron Resonance Heating (ECRH), Ion Cyclotron Resonance Frequency heating (ICRF) and Neutral Beam Injection (NBI). The new ITER research plan is based on a staged approach including two Pre-Fusion Power Operation phases PFPO-1 and PFPO-2 consisting of hydrogen and helium plasmas. The ITER fusion operation phases, i.e. deuterium and deuterium-tritium plasmas, are not covered in the present analysis.

Efficient fusion performance relies on achieving an improved confinement regime, i.e. the so-called H-mode. The L-H power threshold is predicted by scaling laws derived from experimental database and mostly depends on the core density, the plasma surface area and the toroidal magnetic field [1].

Three main magnetic fields are now under consideration to improve H-mode access capabilities in the non-active phase: $B_{0}=1.8 \mathrm{~T}, 2.65 \mathrm{~T}$ and $5.3 \mathrm{~T}$. The $5 \mathrm{MA} / 1.8 \mathrm{~T}$ operation is aimed at enabling $\mathrm{H}$-mode access early in the plan, i.e. in the PFPO-1 phase where only ECRH and ICRF should be available (20 MW of ECRH and possibly $10 \mathrm{MW}$ of ICRF if the PFPO-1 installation of one IC antenna is confirmed). The PFPO-2 phase will benefit from the full baseline heating capabilities, i.e. ECRH, ICRF and NBI heating providing a total auxiliary power of $73 \mathrm{MW}$. A number of ICRF heating schemes have been investigated for these magnetic fields, both in hydrogen and helium plasmas. The expected RF absorption efficiencies of each of these schemes, based on 1D RF wave modelling [2], is reported here.

\footnotetext{
Corresponding author: mireille.schneider@iter.org
}

\section{ICRF heating schemes}

Transport simulations have been carried out using the METIS 0.5D transport code [3], which combines a 1D current diffusion solver, a 2D equilibrium solver and a hybrid $0 \mathrm{D} / 1 \mathrm{D}$ calculation of heat transport dynamics, based on scaling laws. These simulations have provided a consistent initial set of temperatures and densities that are used for ICRF wave calculations [4], for which central core values are displayed in table 1 as a reference for scenarios covered in the present document.

Table 1. Central electron and ion temperatures and densities for all scenarios covered by this analysis.

\begin{tabular}{|c|c|c|c|c|c|c|c|c|}
\hline$B_{0}(T)$ & \multicolumn{2}{|c|}{5.3} & \multicolumn{2}{|c|}{2.65} & \multicolumn{2}{|c|}{1.8} & 3 & 3.3 \\
\hline $\mathrm{I}_{\mathrm{p}}$ (MA) & \multicolumn{2}{|c|}{15} & \multicolumn{2}{|c|}{7.5} & \multicolumn{2}{|c|}{5} & 8.5 & 9.5 \\
\hline$P_{\text {AUX }}(M W)$ & \multicolumn{6}{|c|}{30} & \multicolumn{2}{|c|}{73} \\
\hline Main ion & $\mathrm{H}$ & $\mathrm{He}$ & $\mathrm{H}$ & $\mathrm{He}$ & $\mathrm{H}$ & $\mathrm{He}$ & $\mathrm{H}$ & $\mathrm{H}$ \\
\hline $\mathrm{Te}^{0}(\mathrm{keV})$ & 10 & 13 & 7.2 & 11 & 14 & 16 & 14 & 11 \\
\hline $\mathrm{Ti}^{0}(\mathrm{keV})$ & 12 & 16 & 6.0 & 12 & 7.0 & 8.0 & 10 & 9.3 \\
\hline$n e^{0}\left(10^{19} \mathrm{~m}^{-3}\right)$ & 5.6 & 5.5 & 2.8 & 3.0 & 1.9 & 1.9 & 3.2 & 3.4 \\
\hline$n i^{0}\left(10^{19} \mathrm{~m}^{-3}\right)$ & 5.4 & 2.9 & 2.7 & 1.7 & 1.8 & 1.0 & 2.2 & 2.3 \\
\hline
\end{tabular}

ICRF wave calculations have been performed with the TOMCAT 1D and TORIC 2D ICRF codes $[2,5]$. In this analysis, only the core Single Pass Absorption (SPA), summed over electrons and ion species, is included, since it has been demonstrated to reliably quantify the quality of a heating scheme when compared to experiment, see e.g. [6]. All concentrations are given with respect to the electron density.

The ability of the antenna system to couple ICRF power to these plasmas through the edge region is not discussed in the present paper. 
a) $5.3 T$

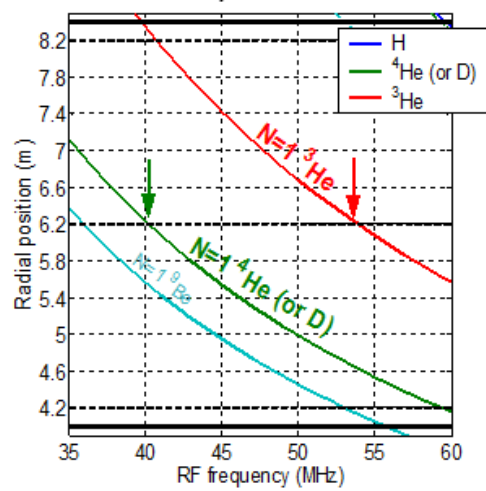

b) $2.65 \mathrm{~T}$

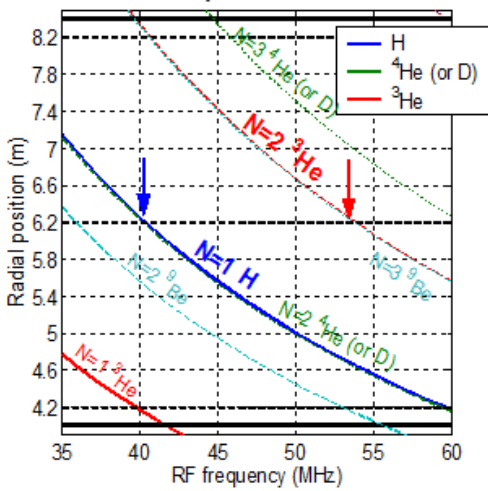

c) $1.8 \mathrm{~T}$

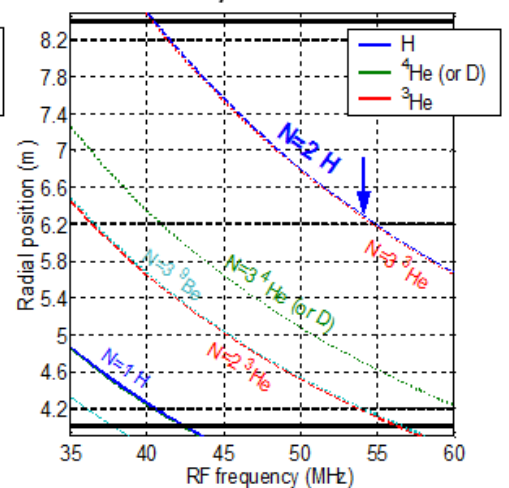

Fig. 1. Cyclotron resonance layers of $\mathrm{H}, \mathrm{He}^{4}, \mathrm{He}^{3}$ and $\mathrm{Be}^{9}$ ions as a function of the ICRF wave frequency at (a) 5.3T, (b) $2.65 \mathrm{~T}$ and (c) $1.8 \mathrm{~T}$ for left / middle / right figures respectively.

Various ion species have been taken into account to explore the best ICRF heating schemes in the ITER nonactive phase: $\mathrm{H}, \mathrm{He}^{4}, \mathrm{He}^{3}$ and $\mathrm{Be}^{9}$. Majority ions can be heated at harmonics of the cyclotron resonance, while fundamental majority heating is inefficient due to the screening effect, i.e. when the wave electric field component rotating in the same sense as the ions vanishes at the resonance location of the majority ion [7]. Other ICRF heating schemes rely on the presence of a minority species with a charge-to-mass ratio different from the majority ion one. These are the two-ion minority heating schemes. Fundamental ion heating schemes typically work best at reduced concentration while harmonic heating requires preheating or a large ion population. $\mathrm{H}-\mathrm{He}^{4}$ mixtures have also been explored to investigate the three-ion minority heating schemes, based on the following fast wave property: if the Lcutoff layer of a two-ion plasma is located close to the fundamental cyclotron resonance of a third species, the latter, if present in small quantities, absorbs almost all the power [8]. Majority species, two-ion and three-ion heating schemes have been investigated at 5.3T, 2.65T and $1.8 \mathrm{~T}$, as described in the next paragraphs. Resonances of all considered ions are displayed in Figure 1 for the three values of the magnetic field as a function of the ICRF wave frequency, of which the accessible range in ITER is $40-55 \mathrm{MHz}$.

\subsection{Heating schemes at a magnetic field of 5.3T}

As illustrated in Figure 1.a, central heating can be achieved at 5.3T for fundamental resonance of $\mathrm{He}^{3}$ at 53 $\mathrm{MHz}$ or fundamental resonance of $\mathrm{He}^{4}$ at $40 \mathrm{MHz}$. Offaxis fundamental $\mathrm{Be}^{9}$ heating is also possible at $40 \mathrm{MHz}$. Characteristics of associated heating schemes are summarized in Table 2 and subsequently discussed.

\subsubsection{Hydrogen plasmas}

Fundamental minority $\mathrm{Be}^{9}$ heating exhibits a low absorption (SPA < 0.4) with dominant electron heating for a $\mathrm{Be}^{9}$ level of $0.5 \%$, which degrades at higher $\mathrm{Be}^{9}$ concentration, leading to poor ICRF heating at full field.

Inverted schemes such as $\mathrm{He}^{3}$ and $\mathrm{He}^{4}$ heating in hydrogen are more appropriate. They are sensitive to the level of background impurity species, as observed at JET with a $\mathrm{C}$-wall $[9,10]$ and Be-wall $[11,12]$. Hence, the presence of $\mathrm{Be}^{9}$ impurities in hydrogen influences the $\mathrm{He}^{4}$ and $\mathrm{He}^{3}$ cyclotron absorption in a similar way as $\mathrm{D}$ or $\mathrm{He}^{4}$ dilution helps the $\mathrm{He}^{3}$ absorption in the $\mathrm{D}$ or $\mathrm{He}^{4}$ $\left(\mathrm{He}^{3}\right)-\mathrm{H}$ three-ion scheme. An example is given in Figure 2, which shows that the higher the background $\mathrm{Be}^{9}$ level, the lower the $\mathrm{He}^{4}$ concentration can be, with equivalent absorption. There is no precise estimate of the $\mathrm{Be}^{9}$ level in ITER, assumed to be $\sim 2 \%$ in the core plasma transport modelling.

Table 2. Performance of various ICRF heating schemes at 15 MA / 5.3 T. Shaded cells highlight high SPA schemes.

\begin{tabular}{|c|c|c|c|c|}
\hline $\begin{array}{c}\text { Main } \\
\text { ion }\end{array}$ & $\begin{array}{l}\text { Heating } \\
\text { scheme }\end{array}$ & $\begin{array}{c}\mathbf{f}_{\mathrm{IC}} \\
(\mathrm{MHz}) \\
\end{array}$ & SPA & \begin{tabular}{|c|c|}
$\begin{array}{c}\text { Constraints and } \\
\text { optimal conditions }\end{array}$ \\
\end{tabular} \\
\hline \multirow{4}{*}{$\mathbf{H}$} & $\begin{array}{l}\mathrm{n}=1 \min \mathrm{He}^{3} \\
\mathrm{He}^{4}-\left(\mathrm{He}^{3}\right)-\mathrm{H}\end{array}$ & 53 & $\sim 0.95$ & $\begin{array}{c}X\left[\mathrm{He}^{3}\right]<1 \% \\
X\left[\mathrm{He}^{4}\right] \sim 10-15 \%\end{array}$ \\
\hline & $\begin{array}{l}\mathrm{n}=1 \min \mathrm{He}^{4} \\
\left(\mathrm{He}^{4}\right)-\mathrm{H} \text { and } \\
\mathrm{Be}^{9}-\left(\mathrm{He}^{4}\right)-\mathrm{H}\end{array}$ & 41 & $0.6-0.8$ & $\begin{array}{c}X\left[\mathrm{He}^{4}\right] \sim 0.1-2 \% \\
\text { Depends on } \mathrm{Be}^{9} \\
\text { level (see Figure 2) }\end{array}$ \\
\hline & $\begin{array}{c}\mathrm{n}=1 \min \mathrm{He}^{3} \\
\left(\mathrm{He}^{3}\right)-\mathrm{H}\end{array}$ & 53 & $\begin{array}{c}\sim 0.8 \text { at } \\
X\left[\mathrm{Be}^{9}\right] \sim 1 \%\end{array}$ & $\begin{array}{c}X\left[\mathrm{He}^{3}\right] \sim 2-4 \% \\
\text { Depends on } \\
\mathrm{Be}^{9} \text { level } \\
\end{array}$ \\
\hline & $\begin{array}{c}\mathrm{n}=1 \min ^{9} \mathrm{Be}^{9} \\
\left(\mathrm{Be}^{9}\right)-\mathrm{H}\end{array}$ & 40 & $\begin{array}{c}<0.4 \text { at } \\
X\left[\mathrm{Be}^{9}\right] \sim 0.5 \%\end{array}$ & Low damping rate \\
\hline \multirow{3}{*}{$\mathrm{He}^{4}$} & $\begin{array}{c}\mathrm{n}=1 \min \mathrm{He}^{3} \\
\left(\mathrm{He}^{3}\right)-\mathrm{He}^{4}\end{array}$ & 53 & $\sim 0.8$ & $X\left[\mathrm{He}^{3}\right] \sim 4-5 \%$ \\
\hline & $\begin{array}{c}\mathrm{n}=1 \min \mathrm{Be}^{9} \\
\left(\mathrm{Be}^{9}\right)-\mathrm{He}^{4}\end{array}$ & 40 & $<0.25$ & Low damping rate \\
\hline & $\mathrm{n}=1$ maj $\mathrm{He}^{4}$ & 40 & $\sim 0.2$ & $\begin{array}{l}\text { Low damping rate } \\
\left(\mathrm{E}_{+} \text {screening }\right)\end{array}$ \\
\hline
\end{tabular}

The SPA for the $\left({ }^{3} \mathrm{He}\right)-\mathrm{H}$ scheme is computed to maximize to $\sim 0.8$ for an $\mathrm{He}^{3}$ concentration of $\sim 2-4 \%$ assuming $1 \%$ of $\mathrm{Be}^{9}$. Operating at lower $\mathrm{He}^{3}$ concentrations would lead to a lower efficiency but may be desirable to limit the operation costs. As discussed above, the $\mathrm{He}^{3}$ concentration can be reduced with equivalent efficiency if the $\mathrm{Be}^{9}$ concentration is higher $[10,12]$. Similarly, heating $\mathrm{He}^{4}$ as a minority in hydrogen is possible. While this regime was not accessible in JET$\mathrm{C}$ wall operation [13] (Z/A ratio for $\mathrm{C}$ is the same as $\mathrm{He}^{4}$ and $D$ ), changing the main intrinsic low- $Z$ impurity from $\mathrm{C}$ to $\mathrm{Be}^{9}$ allows this scheme to work. Indeed, since $(Z / A)_{\mathrm{Be} 9}<(Z / A)_{\mathrm{He} 4}<(Z / A)_{\mathrm{H}}, \mathrm{He}^{4}$ ions can be effectively heated at very low concentrations $(\sim 0.1-0.2 \%)$ via the $\mathrm{Be}^{9}-\left(\mathrm{He}^{4}\right)-\mathrm{H}$ scheme provided the core $\mathrm{Be}^{9}$ concentration

Corresponding author: mireille.schneider@iter.org 
is $\sim 2 \%$ (see Figure 2). If $\mathrm{Be}^{9}$ level is low $(<0.5 \%$ ), then the absorption is maximized at higher $X\left[\mathrm{He}^{4}\right] \sim 1 \%$. Note that at $X\left[\mathrm{Be}^{9}\right]>3 \%$, minority heating of $\mathrm{He}^{4}$ ions becomes inefficient. Injecting $\mathrm{Ne}^{22}$ isotope $(Z / A$ close to that for $\left.\mathrm{Be}^{9}\right)$ could be an option to operate at very low $\mathrm{He}^{4}$ levels, since controlling ${ }^{9} \mathrm{Be}$ is unlikely.

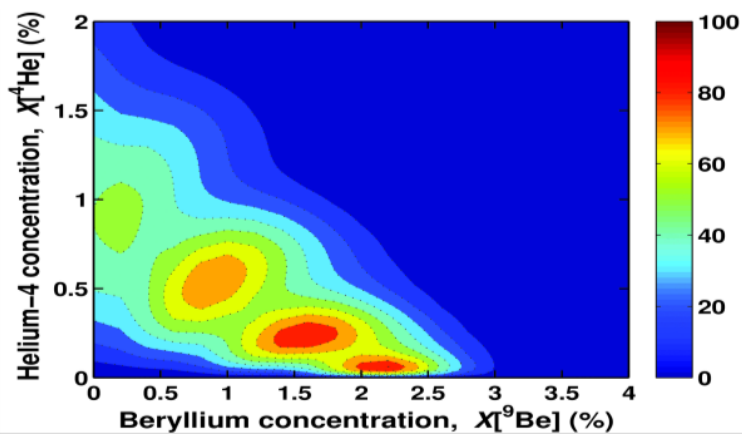

Fig. 2. Absorption by $\mathrm{He}^{4}$ in $\mathrm{H}$ wrt $X\left[\mathrm{Be}^{9}\right]$ and $X\left[\mathrm{He}^{4}\right]$.

The three-ion heating scheme offers a more interesting option as its efficiency relies on very low minority concentration: heating $\mathrm{He}^{3}$ ions with $X\left[\mathrm{He}^{3}\right]<$ $1 \%$ in $\mathrm{H}-\mathrm{He}^{4}$ plasmas $\left(X\left[\mathrm{He}^{4}\right] \sim 10-15 \%\right)$ provides a SPA of 0.95 making it the best absorption scheme, as experimentally demonstrated at JET and C-mod [14].

However, controlling the $\mathrm{He}^{3}$ concentration in the presence of $\mathrm{He}^{4}$ is challenging, since spectroscopy measurement can generally not distinguish them. They may however be discriminated by their different widths in wavelengths since $\mathrm{He}^{3}$ ions are ICRF-accelerated while $\mathrm{He}^{4}$ ions remain thermal [15]. An alternative is to inject a prepared $\mathrm{He}^{4}: \mathrm{He}^{3}$ mixture in the machine.

\subsubsection{Helium plasmas}

Fundamental majority $\mathrm{He}^{4}$ heating exhibits a low absorption (SPA $\sim 0.24$ ) due to the $E_{+}$screening effect, as discussed above. The situation may improve at higher temperatures due to enhanced Doppler-broadening, taking the vanishing $E_{+}$point away from the resonance, as observed in JET-C in NBI preheated plasmas [16].

Fundamental minority $\mathrm{Be}^{9}$ heating presents a $\mathrm{SPA}<$ 0.25 with dominant electron heating. Hence, the best heating scheme in helium at $5.3 \mathrm{~T}$ is fundamental minority $\mathrm{He}^{3}$ with a SPA of 0.8 . It however requires $\mathrm{He}^{3}$ concentration $\sim 4-5 \%$ which is scarce and costly.

\subsection{Heating schemes at a magnetic field of 2.65T}

Figure 1.b indicates that, at 2.65T, central deposition can be achieved with fundamental $\mathrm{H}$ or second harmonic $\mathrm{He}^{4}$ heating at $40 \mathrm{MHz}$, and with second harmonic $\mathrm{He}^{3}$ heating at $53 \mathrm{MHz}$. Characteristics and performance of investigated heating schemes are summarized in Table 3.

\subsubsection{Hydrogen plasmas}

Fundamental majority $\mathrm{H}$ heating exhibits a low absorption (SPA $\sim 0.22$ ) due to the screening effect. Again, the screening could be reduced by the Dopplerbroadening at higher temperature but it has not been investigated yet. Second harmonic minority $\mathrm{He}^{3}$ heating provides no significant improvement with a SPA $<0.25$, even at high $\mathrm{He}^{3}$ concentration. Both schemes have been tested in JET-C and the poor heating performance was confirmed [6]. Finally, second harmonic minority $\mathrm{He}^{4}$ heating is a better heating scheme, providing a SPA still below 0.5 and with a dominant electron heating, leading to a very broad deposition. Thus, there is no efficient ICRF scheme at $2.65 \mathrm{~T}$ in hydrogen. For this reason, optional schemes are envisaged at $3 \mathrm{~T} / 3.3 \mathrm{~T}$ to provide an operational space close to half field with an efficient ICRF heating scheme, as described in section 2.4.

Table 3. Performance of various ICRF heating schemes at 7.5 MA / 2.65T. Shaded cells highlight high SPA schemes.

\begin{tabular}{|c|c|c|c|c|}
\hline $\begin{array}{c}\text { Main } \\
\text { ion }\end{array}$ & $\begin{array}{l}\text { Heating } \\
\text { scheme }\end{array}$ & $\begin{array}{c}\mathbf{f}_{\mathrm{IC}} \\
(\mathbf{M H z})\end{array}$ & SPA & $\begin{array}{c}\text { Constraints and } \\
\text { optimal conditions }\end{array}$ \\
\hline \multirow{3}{*}{$\mathbf{H}$} & $\mathrm{n}=2 \min \mathrm{He}^{4}$ & 40 & $<0.5$ & $\begin{array}{l}\text { Even at high } \mathrm{X}\left[\mathrm{He}^{4}\right] \text {; } \\
\text { dominant on electrons }\end{array}$ \\
\hline & $\mathrm{n}=2 \mathrm{~min} \mathrm{He}^{3}$ & 53 & $<0.25$ & Even at high $\mathrm{X}\left[\mathrm{He}^{3}\right]$ \\
\hline & $\mathrm{n}=1$ maj $\mathrm{H}$ & 40 & $\sim 0.22$ & $\begin{array}{l}\text { Low damping rate } \\
\text { (E } \mathrm{E}_{+} \text {screening) }\end{array}$ \\
\hline \multirow{3}{*}{$\mathrm{He}^{4}$} & $\mathrm{n}=1 \min \mathrm{H}$ & 40 & $\sim 1$ & $\mathrm{X}[\mathrm{H}] \sim 2-8 \%$ \\
\hline & $\mathrm{n}=2$ maj $\mathrm{He}^{4}$ & 40 & 0.78 & - \\
\hline & $\mathrm{n}=2 \min \mathrm{He}^{3}$ & 53 & $>0.6$ & $\begin{array}{c}\mathrm{X}\left[\mathrm{He}^{3}\right]>5 \% \text {, off-axis } \\
\mathrm{He}^{4} \text { absorption }\end{array}$ \\
\hline
\end{tabular}

\subsubsection{Helium plasmas}

Second harmonic minority $\mathrm{He}^{3}$ heating displays a SPA of 0.6 with rather high concentration of $\mathrm{He}^{3}$, here above $5 \%$, hence this scheme should not be favoured. Second harmonic majority $\mathrm{He}^{4}$ heating shows a SPA of 0.78 , making it a suitable candidate. Finally, fundamental minority $\mathrm{H}$ heating at $40 \mathrm{MHz}$ is the best candidate with a SPA close to 1 and $X[\mathrm{H}] \sim 2-8 \%$. The scheme could probably still be efficient at higher $\mathrm{H}$ concentration, which may not be avoidable due to the dilution effect when injecting hydrogen pellets into helium plasmas.

\subsection{Heating schemes at a magnetic field of $1.8 \mathrm{~T}$}

Operating at low magnetic field of $1.8 \mathrm{~T}$ may enable $\mathrm{H}$ mode operation during the PFPO-1 phase where auxiliary heating will be provided by $20 \mathrm{MW}$ of ECRH and probably $10 \mathrm{MW}$ of ICRF (one IC antenna may be installed for this phase but it is still under evaluation). Operating at low density is essential to minimize the L-H power threshold. $40 \%$ of the Greenwald density is considered as optimal as described in [17]. The threshold rollover at lower density can be due to the strong electron-ion decoupling, leading to $T_{e} \gg T_{i}$, where TEM and ETG modes may play a role and METIS scaling laws are beyond their validity domain. Hence, kinetic profiles used for this modelling need comparison with other transport codes. Operating at such low magnetic field induces an overcompensation of the magnetic field ripple by ferromagnetic inserts, leading to a ripple of the order of $-1.3 \%$ which could enhance fast ion losses, still to be quantified. In addition, low density means low collisionality, further reducing the fast ion confinement, potentially leading to enhanced RFinduced plasma wall interaction [18].

As illustrated in Figure 1.c, central resonances are available at $1.8 \mathrm{~T}$ for third harmonic $\mathrm{He}^{4}$ at $40 \mathrm{MHz}$, and 
second harmonic $\mathrm{H}$ or third harmonic $\mathrm{He}^{3}$ at $55 \mathrm{MHz}$. All these schemes are summarized in Table 4.

Table 4. Performance of various ICRF heating schemes at 5 MA / 1.8T. Shaded cells highlight high SPA schemes.

\begin{tabular}{|c|c|c|c|c|}
\hline $\begin{array}{c}\text { Main } \\
\text { ion }\end{array}$ & $\begin{array}{c}\text { Heating } \\
\text { scheme }\end{array}$ & $\begin{array}{c}\mathbf{f}_{\text {IC }} \\
(\mathbf{M H z})\end{array}$ & SPA & $\begin{array}{c}\text { Constraints and } \\
\text { optimal conditions }\end{array}$ \\
\hline \multirow{2}{*}{$\mathbf{H}$} & $\mathrm{n}=2$ maj H & 53 & $\sim 1$ & - \\
\cline { 2 - 5 } & $\mathrm{n}=3$ min $\mathrm{He}^{4}$ & 40 & $\sim 0.5$ & $\begin{array}{c}\text { Even at high } \mathrm{X}\left[\mathrm{He}^{4}\right] ; \\
\text { dominant on electrons }\end{array}$ \\
\hline \multirow{3}{*}{$\mathbf{H e}^{4}$} & $\mathrm{n}=2$ min H & 53 & $\sim 1$ & $X[\mathrm{H}]=5 \%$ \\
\cline { 2 - 5 } & $\mathrm{n}=3$ maj He & 40 & $\sim 0.77$ & Dominant el \\
\cline { 2 - 5 } & $\mathrm{n}=3$ min $\mathrm{He}^{3}$ & 53 & $>0.7$ & $\begin{array}{c}\text { Even at high } X\left[\mathrm{He}^{3}\right] ; \\
\text { dominant on electrons }\end{array}$ \\
\hline
\end{tabular}

\subsubsection{Hydrogen plasmas}

Third harmonic minority $\mathrm{He}^{4}$ heating exhibits a SPA of 0.5 with dominant electron heating, even at high $\mathrm{He}^{4}$ concentration. The best scheme is second harmonic majority $\mathrm{H}$ heating with a very good SPA close to 1 , making it an excellent scheme, provided the fast ions generated by harmonic heating are properly confined.

\subsection{Helium plasmas}

Third harmonic minority $\mathrm{He}^{3}$ heating shows a SPA $\sim 0.7$ with dominant electron heating $(>0.8)$, even at high $\mathrm{He}^{3}$ concentration: in this case and more generally when there is no adequate ion resonance, one can rely on Fast Wave Electron Heating and avoid $\mathrm{He}^{3}$ injection. This generates broader deposition profiles but with an overall good absorption. Third harmonic majority $\mathrm{He}^{4}$ heating shows a SPA of 0.77 , again with dominant electron heating. Finally, second harmonic minority $\mathrm{H}$ heating shows a SPA close to 1 , making it the best candidate. Good minority heating at cyclotron harmonics is unusual but can be achieved thanks to the beneficial $1 / B_{0}^{2}$ scaling of the Finite Larmor Radius absorption [19].

\subsection{Optional schemes at 3T \& 3.3T in hydrogen}

To compensate the lack of efficient ICRF scheme in hydrogen at $2.65 \mathrm{~T}$, one option is to increase the magnetic field to $3 \mathrm{~T}$ or 3.3T and heat a small amount of $\mathrm{He}^{3}(\sim 1 \%)$ at its fundamental resonance at $40 \mathrm{MHz}$. Minimizing the $\mathrm{He}^{3}$ level to $\sim 0.05 \%$ can be achieved in a $\mathrm{H}-\mathrm{He}^{4}$ mixture with $\sim 10-15 \%$ of $\mathrm{He}^{4}$ ions (three-ion scheme). Under these conditions, the SPA is $\sim 0.8-0.9$ shared between central electron heating and off-axis $\mathrm{He}^{3}$ ion heating on the HFS as illustrated in Figure 3.

These optional heating schemes could offer the possibility to reach $\mathrm{H}$-mode in hydrogen when operating close to half field, enabling long pulse operation and ELM control at $\mathrm{q}_{95}=3$. Adding $10-15 \%$ of $\mathrm{He}^{4}$ reduces the minimum allowable operational density with respect to NBI shinethrough, and could allow access to hydrogenic $\mathrm{H}$-mode operation at lower input power, if observations from recent JET experiments are confirmed [20]. However, tungsten accumulation with reduced central heating needs to be considered and quantified. Furthermore, as discussed above, $\mathrm{He}^{3}$ level control in the presence of $\mathrm{He}^{4}$ may prove challenging. Finally, ion losses are still to be assessed. They can be significant due to off-axis fast trapped ion acceleration [21]. They can however always be reduced by increasing the $\mathrm{He}^{3}$ concentration to reduce the fast ion tail.

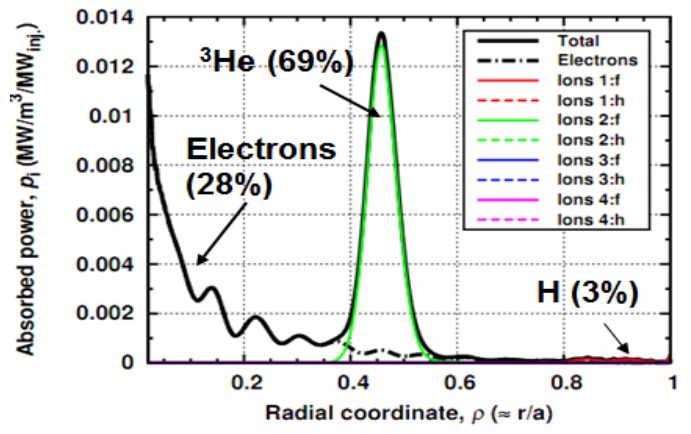

Fig. 3. Wave absorption for fundamental minority $\mathrm{He}^{3}$ heating in an $\mathrm{H}: \mathrm{He}^{4}$ mixture at 3.3T (TORIC run).

\section{Conclusion}

Various ICRF heating schemes for the ITER non-active phase have been investigated. For the ITER ICRF frequency range 40-55 $\mathrm{MHz}$, effective absorption schemes are available in hydrogen and helium at magnetic fields of $5.3 \mathrm{~T}, 2.65 \mathrm{~T}$ and $1.8 \mathrm{~T}$, except for hydrogen operation at $2.65 \mathrm{~T}$. This may be compensated by optional schemes at $3 \mathrm{~T}$ and $3.3 \mathrm{~T}$ with fundamental minority $\mathrm{He}^{3}$ heating in a $\mathrm{H}-\mathrm{He}^{4}$ mixture (three-ion heating scheme). Results at 5MA/1.8T are preliminary as they imply a regime with strong electron / ion decoupling $\left(T_{e}>>T_{i}\right)$ where TEM and ETG modes play a significant role, not covered by METIS scaling laws. Hence, kinetic profiles need to be crosschecked with other transport codes and made self-consistent with heating sources. Furthermore, most of the results presented in this paper have been produced by the TOMCAT 1D code and should be advanced with $2 \mathrm{D}$ full wave computations. Future antenna coupling studies will also contribute to complete the picture.

\section{Acknowledgments}

ITER is a Nuclear Facility INB-174. The views and opinions expressed herein do not necessarily reflect those of the ITER Organization.

\section{References}

1. Y.R. Martin et al, J. of Physics: Conf. Series 123 (2008) 012033

2. D. Van Eester and R. Koch, PPCF 40, 1949-1975 (1998)

3. J.F. Artaud et al 2010 Nucl. Fusion 50043001

4. M. Schneider, $17^{\text {th }}$ ITPA-IOS TG meeting - Naka, Japan (2016)

5. M. Brambilla, PPCF 41, 1-34 (1999).

6. E. Lerche et al, PPCF 54 (2012) 069601 (6pp)

7. T. Stix, Waves in Plasmas, AIP Press (1992)

8. Ye.O. Kazakov et al, Nucl Fusion 55, 032001 (2015)

9. M.-L. Mayoral et al, Nucl. Fusion 46 (2006) S550-S563

10. D. Van Eester et al, PPCF 51 (2009) 044007

11. D. Van Eester et al, EPS 2015 Lisbon (Portugal), P2.117

12. D. Van Eester et al, this conference

13. P. Lamalle et al. Nucl. Fusion 46, 391-400 (2006)

14. Ye.O. Kazakov et al., APS. 61, APS-DPP 2016, San Jose (USA)

15. M. von Hellerman et al., ITPA-EP, Seville (Spain), April 2017.

16. A. Krasilnikov et al, A V Krasilnikov et al 2009 PPCF 51044005

17. F. Ryter et al, Nucl. Fusion 54083003 (2014)

18. E. Lerche et al, AIP Conference proceedings, 1689 (2015) 040003

19. M. Porkolab AIP Conference Proceedings 314, 99 (1994)

20. J. Hillesheim et al.,26 ${ }^{\text {th }}$ IAEA FEC, Kyoto, Japan, 2016., EX/5-2

21. J. Joly et al, this conference. 